\title{
A Study on the Adoption Intention of Tourism Users' Applications
}

\author{
Wang Ruping $^{1^{*}}$, Yang lvzhou ${ }^{2}$, Jiang $\mathbf{y i}^{3}$ \\ ${ }^{1}$ School of Management, China West Normal University, Nanchong 637002,Sichuan, China \\ ${ }^{2}$ School of Mathematical Science s UESTC, University of Electronic Science and Technology of \\ China, Chengdu 610054,Sichuan, China \\ ${ }^{3}$ Imperial College London, South Kensington, London SW7 2AZ.
}

*Corresponding Author: Wang Ruping, School of Management, China West Normal University, Nanchong 637002, Sichuan, China

\begin{abstract}
The mobile application of tourism service (App) has become an important tool for people to obtain travel-related information. However, studies on the reception intention of tourism service apps from the perspective of App product attributes are extremely scarce at present. In view of this, this thesis studies tourism-related applications based on the innovation diffusion theory (IDT). On the basis of the theoretical research, a model of user acceptance behavior of tourism service App was built based on the comparative advantage, compatibility and complexity of innovation perception characteristics (PCI) and the software quality model, and then a model of users' willingness to use tourism service App was established. At the same time, it also explains the influencing factors of users' willingness to use tourism service App, and finds out the core influencing factors and important influencing factors, and provides Suggestions for the developers of tourism service App, which also provides a good theoretical basis for future research in this field.
\end{abstract}

Key words: Mobile Travel App; Adoption Intention; Perceived Characteristics of Innovation (PCI); Software Quality

\section{INTRODUCTION}

In 2019, China's online travel transaction volume reached 1.08665 trillion yuan, with a year-on-year growth of $11.4 \%$. Information collection, itinerary booking, accommodation, transportation, catering, photo editing and travel sharing have constituted the ecological chain of the tourism industry, and the profit point mainly concentrated on the preparatory phase before travel, which has become the most competitive field of the mobile terminals of various tourism services. Therefore, whether from the perspective of developers or the need of market competition, it has become an urgent practical need to further study the factors which affecting tourists' willingness to adopt mobile travel apps. In recent years, a large number of researchers have conducted various researches on mobile travel apps. For example, li dong et al. studied on the factors affecting the download of mobile travel apps by introducing the two variables of self-efficacy and risk perception. Lu et al. combined the Innovation Diffusion Model (IDT), Technology Acceptance Model (TAM), and Social Cognition Theory (SCT) to establish user acceptance model of traveler on tourism app. Amaro and Duarte discussed the factors which influence consumers' purchase of online travel products. Agag and el-masry investigated consumers' willingness to participate in online travel communities and purchase travel products online. Jensen investigated the willingness of travelers to purchase travel products online. Kang et al. investigated the people's willingness to download and use those applications for retail purchase which based on mobile location. However, there is a lack of research on the acceptance intention of mobile travel apps from the perspective of its' product attributes. Therefore, based on previous research results, this thesis further studied the willingness of tourists to use mobile travel applications.

\section{RESEARCH MODELS AND HYPOTHESIS}

\subsection{Research Models}

Rogers proposed the innovation diffusion theory (IDT) in the 1990s. Innovation perception features 
are an important part of the innovation diffusion theory, including comparative advantage, compatibility, complexity, etc., which influenced consumers' willingness to adopt new technologies. At the same time, involvement is considered to be an important factor in stimulating costumers' behavior. Involvement is defined as "a person's perceived relevance of the object based on inherent needs, values and interests". Meanwhile, Zaichkowsky thought that involvement is recognized as the perceived importance of the stimulus. The involvement construct has been investigated in numerous consumer behavior and marketing literature. Involvement can be divided into two categories including cognitive involvement and affective involvement, which have been implemented in the opinion of Zaichkowsky. Jiang et al. believe that consumers' involvement in the website is a prerequisite for them to have a positive attitude towards the website and purchase behavior. Huang, Chou, and Lin (2010) provide insights into the structural relationship among travel bloggers' involvement level, travel bloggers' intention to purchase travel products and the advertising effect from blog messages. Software quality refers to the degree to which the system or components meet users' specific needs or expectations.

According to the purpose of this thesis, based on the innovative integration of the above theories, this study proposed a research model (as shown in figure 1), with ten constructs including comparative advantage, compatibility, complexity, time convenience, social interaction, UI aesthetics, portability, attitude, involvement and adoption intention. The relationship between constructs in this model will be illustrated in the hypothesis section.

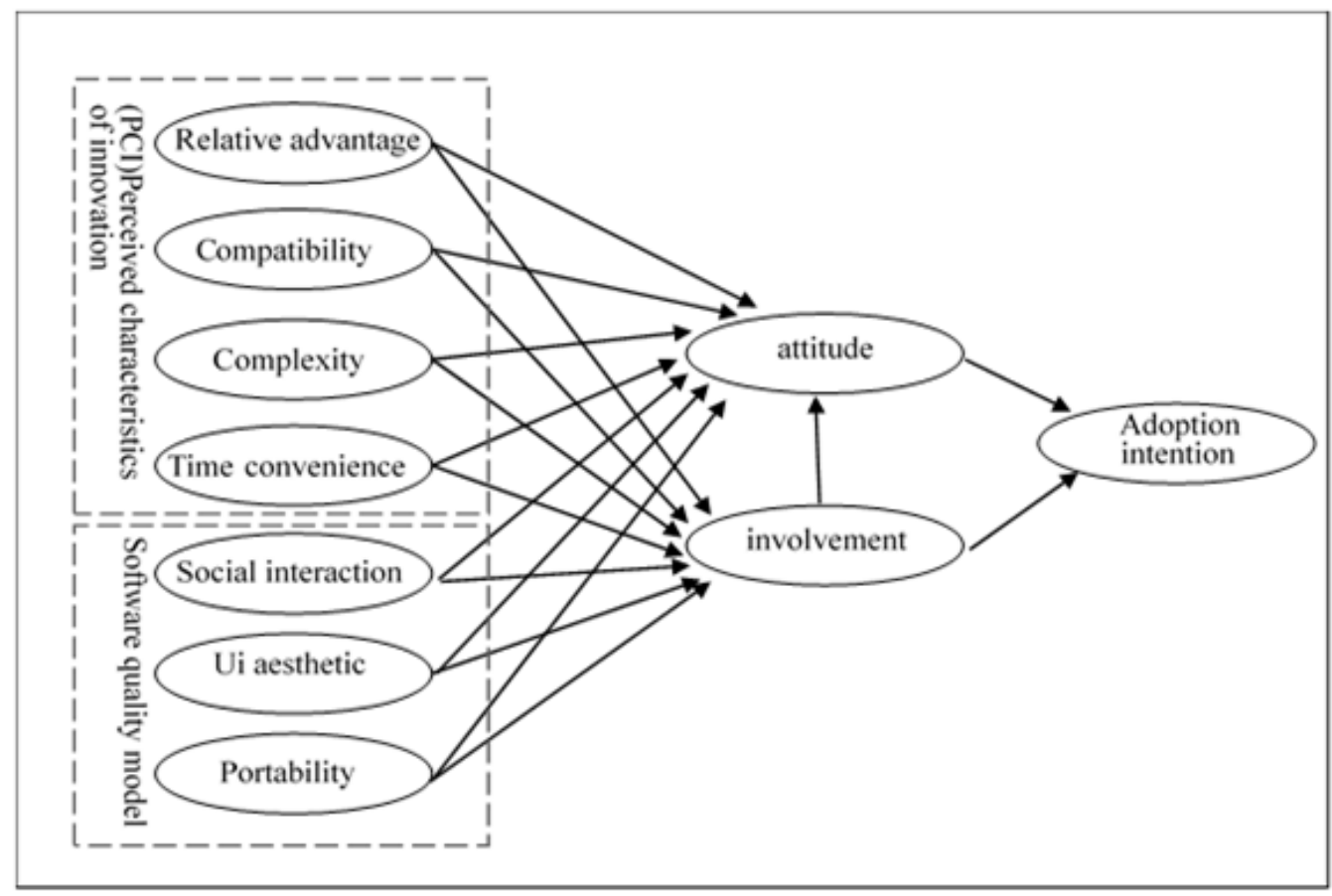

\subsection{Research Hypothesis}

\subsubsection{Relative Advantage and User's Attitude}

Relative advantages, compatibility, and complexity are three factors underpinning the Innovation Diffusion Theory. Relative advantage describes the degree to which an innovation is perceived as being better than the previous ways of performing the same task. In the field of mobile location-based retail applications, a significant and positive relationship between relative advantages and involvement has been verified. The perceived innovation attributes indicate that there is a significant correlation between relative advantages and acceptability. Therefore, we draw the following hypothesis:

H1a: The relative advantages of mobile travel applications have a positive impact on user attitudes.

H1b: Relative advantage of a mobile travel app has a positive influence on users' involvement.

Compatibility describes the extent to which users regard using a mobile travel app as fitting in with their traveling needs and preferences. Kang et al. (2015) found that compatibility is the determinant of consumer emotional and cognitive involvement. Therefore, we have the following hypothesis: 
H2a: Compatibility of a mobile travel app has a positive influence on users' attitude.

$\mathrm{H} 2 \mathrm{~b}$ : Compatibility of a mobile travel app has a positive influence on users' involvement.

The important and positive relationship between perceived ease of use and attitude has been supported by many studies. Premkumar (2015) demonstrate that complexity of a certain product, technology or service can inhibit the intension to adapt it. Based on this, the following assumptions are proposed:

H3a: Complexity of a mobile travel app has a negative influence on users' attitude.

H3b: Complexity of a mobile travel app has a negative influence on users' involvement.

\subsubsection{Software Quality Model and User's Attitude}

Miguel et al. believed that Software quality refers to the extent to which a system or component meets a user's specific needs or expectations. Time convenience represents the relative advantages of mobile transaction services. Previous study concludes that time convenience mediates the effect of service and value (Tojib \& Tsarenko, 2012), which can infer the fact that time convenience plays an irreplaceable role in contemporary business activities. Therefore, we propose the following hypothesis:

H4a The time convenience of the mobile travel app has a positive impact on the user's attitude.

$\mathrm{H} 4 \mathrm{~b}$ The time convenience of mobile travel applications has a positive impact on user involvement.

Social interaction has greatly changed people's lives. The role of social interaction has featured prominently in travel service. Previous studies show that interaction of system-related dimensions and human interaction have a positive influence on consumer psychological engagement. Interaction can be defined as the indispensable features that affect consumers' participation and usage. Therefore, the following hypotheses are developed:

H5a: Social interaction of a mobile travel app has a positive influence on users' attitude.

H5b: Social interaction of a mobile travel app has a positive influence on users' involvement.

The user interface is the design of operating logic and user interface aesthetic. UI design is an important part of user interface design. Users prefer systems with a visually appealing UI, and touchscreen-based visuals are even more attractive for mobile users. Therefore, the following assumptions are proposed:

H6a: Good user interface of a mobile travel app has a positive influence on users' attitude.

H6b: Good user interface of a mobile travel app has a positive influence on users' involvement.

Mobile app portability is defined as an application's ability to be executed on different mobile operating system (OS). It is believed that the ubiquity and portability of mobile apps is closely related to consumers' consumption behavior, which is important in marketing activities. Therefore, we propose the following hypothesis:

H7a: The portability of mobile travel applications has a positive impact on user attitudes.

H7b: The portability of mobile travel applications has a positive impact on user involvement.

\subsubsection{User's Involvement, User's Attitude and User's Willingness to Use}

Bruner and Kumar (2005) suggest that if consumers hold a positive attitude towards a product, they will be more likely to have the intention to adopt the certain product. Consumers along with positive attitude toward travel apps are likely to speed up their adoption intention of travel apps. Therefore, we develep the following hypothesis:

H8: The involvement of mobile travel apps has a positive impact on user attitudes.

H9: The involvement of mobile travel apps has a positive impact on user's intention to use.

H10: The attitude of the mobile travel app has a positive impact on user's willingness to use.

\section{Data Collection}

\subsection{Data Sources}

In this thesis, 803 sample data were collected in the form of questionnaire and field visits to the tourist attractions in chengdu, sichuan province, a famous tourist city in China. The questionnaire survey is 
divided into two parts, one is the basic information part, and the second is the construct measurement part. The results of the latent variables in this study are derived from the literature on mature measurement scales of previous studies. The variables in this study were measured from previous studies and then appropriately adjusted to suit the situation of users using the Travel Services app.

\subsection{Confirmatory Factor Analysis}

The construction measurement part consists of ten latent constructions such as the relative advantage, compatibility, complexity, social interaction, UI aesthetic, time-convenience, portability, involvement, attitude and adoption intention, a total of 37 items. We took a descriptive analysis of the 803 effective questionnaires. Due to the complexity was the reverse measurement, so the data was reversed when analyzing. Among the 37 items, 30 items the minimum value is 1,7 items the minimum is $2 ; 35$ items the maximum value is 7,2 items the maximum is 6 . Complexity items value between 2 and 3 , with a standard deviation around 1.00. The rest items value between 5 and 6 , with a standard deviation around 1.00 .

\subsection{Reliability Analysis}

We adopt the maximum likelihood method to test the measurement model. The first part in evaluating a research model is to present the measurement model results to examine the reliability and validity of the measures used to represent each construction. Generally, the reliability test investigates the internal consistency within a architecture. To assess the reliability the Cronbach's Alpha $(\alpha)$ is computed. Table 1 shows the results of reliability. All of the constructs' value of Cronbach's Alpha uniformly high as the Cronbach's Alpha range from 0.89 to 0.94 , thus surpassing the thresholds of o.70. The factor loadings of all items range from 0.80 to 0.92 , all items loading are greater than the recommend level of 0.7. All of the above evidences showed that the measurement model had acceptable reliability.

Table1. The factor loading and results of reliability

\begin{tabular}{|c|c|c|c|c|c|c|}
\hline Construct & Item & Loading & $p$ & Cronbach's $\alpha$ & Composite reliability & AVE \\
\hline \multirow{4}{*}{ adoption intention } & INT1 & 0.83 & 0.00 & \multirow[t]{4}{*}{0.92} & \multirow[t]{4}{*}{0.92} & \multirow[t]{4}{*}{0.86} \\
\hline & INT2 & 0.89 & 0.00 & & & \\
\hline & INT3 & 0.90 & 0.00 & & & \\
\hline & INT4 & 0.83 & 0.00 & & & \\
\hline \multirow{5}{*}{ attitude } & ATT1 & 0.82 & 0.00 & \multirow[t]{5}{*}{0.94} & \multirow[t]{5}{*}{0.94} & \multirow[t]{5}{*}{0.87} \\
\hline & ATT2 & 0.87 & 0.00 & & & \\
\hline & ATT3 & 0.92 & 0.00 & & & \\
\hline & ATT4 & 0.92 & 0.00 & & & \\
\hline & ATT5 & 0.80 & 0.00 & & & \\
\hline \multirow{3}{*}{ involvement } & INV1 & 0.86 & 0.00 & \multirow[t]{3}{*}{0.89} & \multirow[t]{3}{*}{0.89} & \multirow[t]{3}{*}{0.85} \\
\hline & INV2 & 0.87 & 0.00 & & & \\
\hline & INV3 & 0.83 & 0.00 & & & \\
\hline \multirow{4}{*}{ relative advantage } & REA1 & 0.88 & 0.00 & \multirow[t]{4}{*}{0.93} & \multirow[t]{4}{*}{0.93} & \multirow[t]{4}{*}{0.88} \\
\hline & REA2 & 0.91 & 0.00 & & & \\
\hline & REA3 & 0.91 & 0.00 & & & \\
\hline & REA4 & 0.82 & 0.00 & & & \\
\hline \multirow{3}{*}{ compatibility } & COM1 & 0.89 & 0.00 & \multirow[t]{3}{*}{0.90} & \multirow[t]{3}{*}{0.90} & \multirow[t]{3}{*}{0.87} \\
\hline & COM2 & 0.90 & 0.00 & & & \\
\hline & COM3 & 0.82 & 0.00 & & & \\
\hline \multirow{3}{*}{ complexity } & CEX1 & 0.84 & 0.00 & \multirow[t]{3}{*}{0.89} & \multirow[t]{3}{*}{0.90} & \multirow[t]{3}{*}{0.87} \\
\hline & CEX2 & 0.92 & 0.00 & & & \\
\hline & CEX3 & 0.83 & 0.00 & & & \\
\hline \multirow{3}{*}{ time-convenience } & TIM1 & 0.86 & 0.00 & \multirow[t]{3}{*}{0.92} & \multirow[t]{3}{*}{0.92} & \multirow[t]{3}{*}{0.89} \\
\hline & TIM2 & 0.92 & 0.00 & & & \\
\hline & TIM3 & 0.90 & 0.00 & & & \\
\hline \multirow{3}{*}{ social interaction } & SIN1 & 0.91 & 0.00 & \multirow[t]{3}{*}{0.92} & \multirow[t]{3}{*}{0.92} & 0.89 \\
\hline & SIN2 & 0.91 & 0.00 & & & \\
\hline & SIN3 & 0.85 & 0.00 & & & \\
\hline
\end{tabular}




\begin{tabular}{|c|c|c|c|c|c|c|}
\hline \multirow{6}{*}{ UI aesthetic } & UI1 & 0.82 & 0.00 & \multirow[t]{6}{*}{0.94} & \multirow[t]{6}{*}{0.94} & \multirow[t]{6}{*}{0.85} \\
\hline & UI2 & 0.87 & 0.00 & & & \\
\hline & UI3 & 0.86 & 0.00 & & & \\
\hline & UI4 & 0.85 & 0.00 & & & \\
\hline & UI5 & 0.87 & 0.00 & & & \\
\hline & UI6 & 0.83 & 0.00 & & & \\
\hline \multirow{3}{*}{ portability } & POR1 & 0.83 & 0.00 & \multirow[t]{3}{*}{0.92} & \multirow[t]{3}{*}{0.92} & \multirow[t]{3}{*}{0.89} \\
\hline & POR2 & 0.91 & 0.00 & & & \\
\hline & POR3 & 0.92 & 0.00 & & & \\
\hline
\end{tabular}

\subsection{Validity Analysis}

Convergent and discriminant validity are considered in the second part. Convergent validity is supported by the following: (1) all the factor loading should be significant $(\mathrm{p}<0.001)$ (Table 1); (2) generally speaking, average variance extracted (AVE) meet the recommended benchmark of 0.5 and the square root of average variance extracted (AVE) surpass the recommended level of 0.7. AVE values of 0.5 and higher imply that the latent construct explains more than half of its indictors' variance (Table 1).

Discriminant validity is supported by the two aspects, the measurement items loading should be greater than all of its cross loading, and the square root of the AVE of each latent construct should be higher than the construct's highest correlation with any other latent construct. Table 2 shows the correlation matrix of the structure together with the square root of the AVEs. Each mixture meets this requirement in support of discriminant validity. Thus, a high degree of discriminant validity can be presumed with respect to all the constructs in this study. Therefore, we conclude that measurement model exhibits good convergent validity and discriminant validity and reliability.

Table2. Correlations of the constructs and the square root of AVE

\begin{tabular}{|c|c|c|c|c|c|c|c|c|c|c|}
\hline & 1 & 2 & 3 & 4 & 5 & 6 & 7 & 8 & 9 & 10 \\
\hline 1.intention & 0.927 & & & & & & & & & \\
\hline 2.attitude & 0.627 & 0.933 & & & & & & & & \\
\hline 3.involvement & 0.658 & 0.901 & 0.922 & & & & & & & \\
\hline 4.relative advantage & 0.480 & 0.653 & 0.833 & 0.938 & & & & & & \\
\hline 5.compatibility & 0.542 & 0.700 & 0.888 & 0.777 & 0.933 & & & & & \\
\hline 6.time comvenience & 0.513 & 0.599 & 0.781 & 0.660 & 0.742 & 0.943 & & & & \\
\hline 7.social interaction & 0.468 & 0.490 & 0.655 & 0.472 & 0.598 & 0.576 & 0.943 & & & \\
\hline 8.ui aesthetic & 0.488 & 0.638 & 0.790 & 0.637 & 0.705 & 0.613 & 0.609 & 0.922 & & \\
\hline 9.complexity & 0.365 & 0.444 & 0.556 & 0.476 & 0.458 & 0.414 & 0.325 & 0.506 & 0.933 & \\
\hline 10.portability & 0.277 & 0.376 & 0.524 & 0.491 & 0.473 & 0.456 & 0.299 & 0.476 & 0.515 & 0.943 \\
\hline
\end{tabular}

\section{DATA ANALYSIS AND RESUltS}

This chapter mainly analyzes the collected data and constructs a structural equation model which based on AMOS statistical analysis software to test the research hypothesis and participate in the mediating effect and attitude mediating effect. The results show that participation has a certain mediating effect on the relationship between relative advantage and willingness and attitude has a partial mediating effect on the relationship between relative advantage and willingness.

\subsection{Test of Research Hypothesis}

The path of the structural model is assessed. Each path corresponds to a hypothesis. Each hypothesis has been tested by checking the sign, size, and statistical significance of the path coefficients between each latent variable and the dependent variable. The higher the path coefficient is, the stronger the effect of a predictor latent variable on the dependent variable will be.

$\mathrm{H} 1 \mathrm{a}$ is not supported (path coefficient is -0.302 at $\mathrm{p} \leq 0.001$ ), the sign of the path is opposite to our hypothesis. That means the effect of relative advantage on users' attitude is negative. On the other hand, $\mathrm{H} 1 \mathrm{~b}$ is supported (path coefficient is 1.102 at $\mathrm{p} \leq 0.001$ ), demonstrating that relative advantage has a positive effect on involvement. Similar to relative advantage, the effect of compatibility (path coefficient is -0.350 at $\mathrm{p} \leq 0.001$ ) and portability (path coefficient is -0.306 at $\mathrm{p} \leq 0.001$ ) on attitude is opposite to our hypothesis, the sign shows the negative effect on attitude. Therefore, $\mathrm{H} 2 \mathrm{a}$ and $\mathrm{H} 7 \mathrm{a}$ are not supported. Meanwhile, the path from compatibility (path coefficient is 1.269 at $\mathrm{p} \leq 0.001$ ) and portability (path coefficient is 0.779 at $\mathrm{p} \leq 0.001$ ) to involvement is significant, so $\mathrm{H} 2 \mathrm{~b}$ and $\mathrm{H} 7 \mathrm{~b}$ are 
verified. $\mathrm{H} 3 \mathrm{a}$ and $\mathrm{H} 3 \mathrm{~b}$ predict a positive effect of complexity to attitude and involvement. The path from complexity to involvement is supported (path coefficient is 0.693 at $p \leq 0.001$ ). However, the path from complexity to attitude is not supported $(\mathrm{p}=0.091>0.001)$. $\mathrm{H} 4 \mathrm{a}$ and $\mathrm{H} 4 \mathrm{~b}$ postulate a positive effect of time convenience to attitude and involvement. The path from time convenience to involvement is supported (path coefficient is 1.086 at $\mathrm{p} \leq 0.001$ ), and the path from time convenience to attitude is not supported ( $\mathrm{p}=0.004>0.001)$. The same goes to the effect of social interaction and UI aesthetic on attitude and involvement. The path from social interaction to attitude $(\mathrm{p}=0.003>0.001)$ and the path from UI aesthetic to attitude $(\mathrm{p}=0.088>0.001)$ are not supported. And the positive effect of social interaction (path coefficient is 1.263 at $\mathrm{p} \leq 0.001$ ) and UI aesthetic (path coefficient is 0.991 at $\mathrm{p} \leq 0.001$ ) on involvement is significant, as a result, $\mathrm{H} 5 \mathrm{~b}$ and H6b are supported, actually H5a and H6a are not supported. H8 (path coefficient is 0.727 at $\mathrm{p} \leq 0.001$ ) and $\mathrm{H} 9$ (path coefficient is 0.150 at $\mathrm{p} \leq 0.001$ ) are supported, hence, involvement has a positive effect on attitude and intention. The path from attitude to intention conforms to our expected (path coefficient is 0.589 at $\mathrm{p} \leq 0.001$ ), then, H10 is supported. The results are summarized in Figure 2.

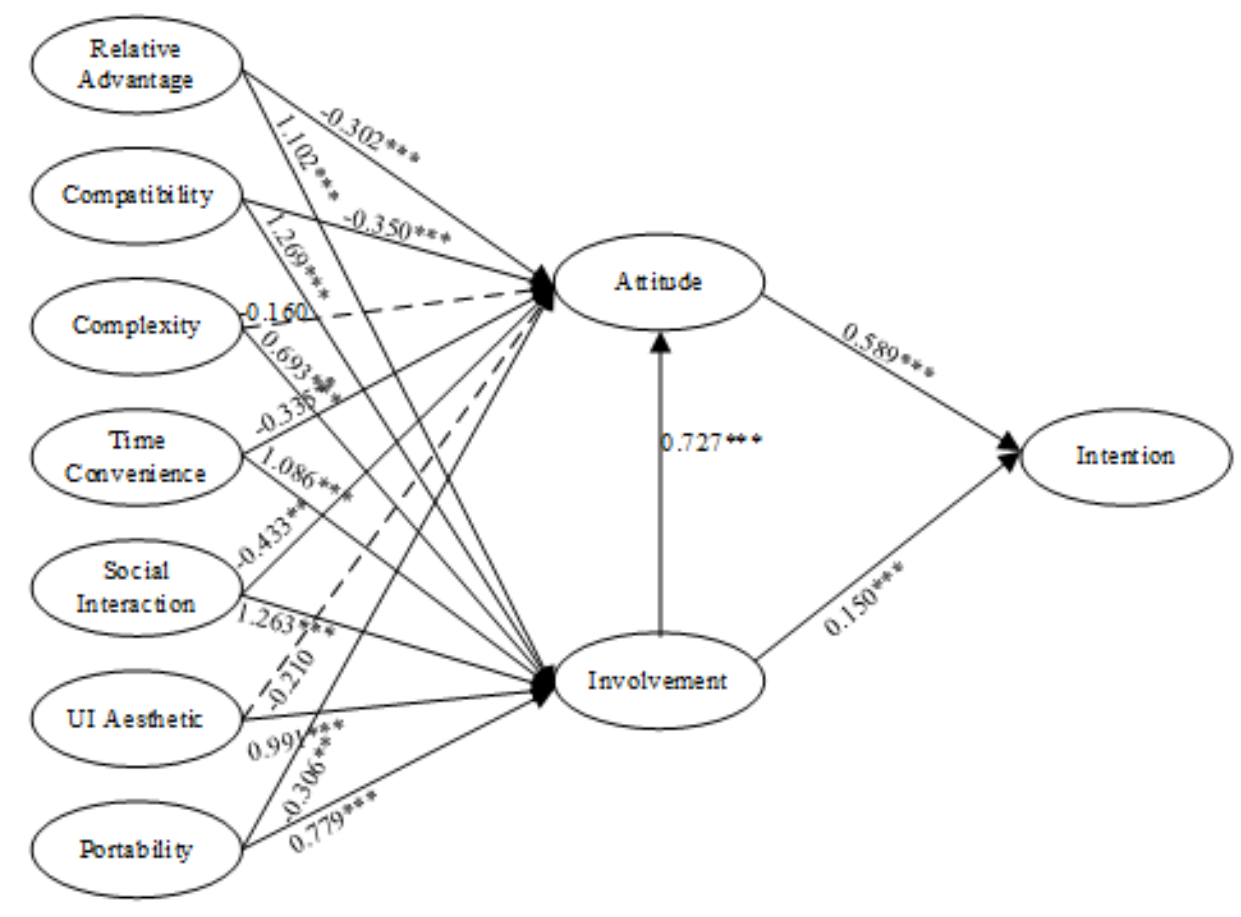

Figure2. The model results

The results show that the structural model is highly fitted and most of the hypotheses are verified. It is easier to grasp the conception of complexity affecting involvement negatively. When people use a certain product, if they feel that the operation is complicated, the experience of the product will be reduced, that is, the user's involvement will decrease as the complexity of the product is increased.

\subsection{Test of Mediation: Involvement}

We tested the mediation effect by using Baron and Kenny's method. Formula1-3 are used to verify the mediation effect on the relationship between independent variable (IV) and dependent variable (DV). to test the mediation effect of involvement, we first need to test the significance of coefficient $\mathrm{c} 1$ in Formula 1. If $\mathrm{c} 1$ is significant, then we need to further test the significance of coefficient $\mathrm{a} 1 \mathrm{and} \mathrm{b} 1$ in Formula 2 and 3. If a 1 and b1 are significant, then we must testify the mediating effect according to c2. If at least one of $\mathrm{a} 1$ and $\mathrm{b} 1$ is not significant, then we must verify the mediating effect through the Sobel test. According to this approach, mediation exists when three things happen: (1) the independent variable (IV) has a significant effect on the dependent variable (DV) when the proposed mediator (M) is not included in the model, (2) IV has a significant effect on M, and (3) when M is included in the model, it has a significant effect on DV, while the relationship IV $\rightarrow$ DV is either significant (partial mediation) or insignificant (full mediation).

The verification of mediation effect of involvement is illustrated in Table 3, Table 4 and Table 5. Table 5-4 show the test for the effect of independent variable (IV) on the dependent variable (DV) when the proposed mediator $(\mathrm{M})$ is not included in the mode. 
For the mediation effect of involvement on the relationship between relative advantage (IV) and intention (DV), according to Formula1 and Table 3, coefficients c1-relative advantage is significant (coefficient is 0.419 at $\mathrm{p} \leq 0.001$ ). Table 4 show the path from IV $\rightarrow \mathrm{M}$, for the path from relative advantage (IV) to involvement (M), coefficient a1-relative advantage is 0.658 at $p \leq 0.001$, in other words, relative advantage (IV) have significant effect on involvement(M). Table 5 illustrate model 3, in this test, c2-relative advantage (coefficient is 0.660 at $\mathrm{p} \leq 0.001$ ) and b1-relative advantage (coefficient is 0.559 at $\mathrm{p} \leq 0.001$ ) is significant. To sum up, involvement has partial mediation effect on the relationship between relative advantage and intention.

Table3. Test for $I V \rightarrow D V$ without involvement

\begin{tabular}{|l|l|l|l|l|l|l|}
\hline DV: intention & Coef. & Std. Err. & $\mathrm{z}$ & \multicolumn{2}{|l|}{$\mathrm{P}>|\mathrm{z}|$} & \multicolumn{2}{|l|}{$[95 \%$ Conf. Interval] } \\
\hline Relative advantage $\rightarrow$ Intention & 0.419 & 0.039 & 10.680 & 0.000 & 0.342 & 0.495 \\
\hline Compatibility $\rightarrow$ Intention & 0.517 & 0.047 & 11.100 & 0.000 & 0.426 & 0.609 \\
\hline Complexity $\rightarrow$ Intention & 0.333 & 0.041 & 8.220 & 0.000 & 0.254 & 0.412 \\
\hline Time convenience $\rightarrow$ Intention & 0.474 & 0.041 & 11.550 & 0.000 & 0.393 & 0.554 \\
\hline Social interaction $\rightarrow$ Intention & 0.588 & 0.052 & 11.330 & 0.000 & 0.486 & 0.689 \\
\hline UI aesthetic $\rightarrow$ Intention & 0.450 & 0.042 & 10.820 & 0.000 & 0.369 & 0.532 \\
\hline Portability $\rightarrow$ Intention & 0.230 & 0.038 & 6.080 & 0.000 & 0.156 & 0.305 \\
\hline
\end{tabular}

Table4. Test for IV $\rightarrow$ involvement

\begin{tabular}{|l|l|l|l|l|l|l|}
\hline M: Involvement & Coef. & Std. Err. & $\mathrm{z}$ & $\mathrm{P}>|\mathrm{z}|$ & {$[95 \%$ Conf. Interval] } \\
\hline Relative advantage $\rightarrow$ Involvement & 0.658 & 0.044 & 14.980 & 0.000 & 0.572 & 0.744 \\
\hline Compatibility $\rightarrow$ Involvement & 0.696 & 0.044 & 15.730 & 0.000 & 0.609 & 0.783 \\
\hline Complexity $\rightarrow$ Involvement & 0.384 & 0.040 & 9.520 & 0.000 & 0.305 & 0.464 \\
\hline Time convenience $\rightarrow$ Involvement & 0.540 & 0.043 & 12.620 & 0.000 & 0.456 & 0.624 \\
\hline Social interaction $\rightarrow$ Involvement & 0.654 & 0.051 & 12.790 & 0.000 & 0.554 & 0.754 \\
\hline UI aesthetic $\rightarrow$ Involvement & 0.566 & 0.043 & 13.150 & 0.000 & 0.481 & 0.650 \\
\hline Portability $\rightarrow$ Involvement & 0.310 & 0.041 & 7.480 & 0.000 & 0.229 & 0.391 \\
\hline
\end{tabular}

Table5. Test for $I V \rightarrow D V$ with involvement

\begin{tabular}{|l|l|l|l|l|l|l|}
\hline & Coef. & Std. Err. & $\mathrm{z}$ & $\mathrm{P}>|\mathrm{z}|$ & \multicolumn{2}{l|}{$[95 \%$ Conf. Interval] } \\
\hline Relative advantage $\rightarrow$ Involvement & 0.660 & 0.042 & 15.540 & 0.000 & 0.577 & 0.743 \\
\hline Involvement $\rightarrow$ Intention & 0.559 & 0.042 & 13.220 & 0.000 & 0.476 & 0.642 \\
\hline Compatibility $\rightarrow$ Involvement & 0.707 & 0.044 & 15.970 & 0.000 & 0.620 & 0.794 \\
\hline Involvement $\rightarrow$ Intention & 0.579 & 0.042 & 13.800 & 0.000 & 0.496 & 0.661 \\
\hline Complexity $\rightarrow$ Involvement & 0.392 & 0.039 & 9.990 & 0.000 & 0.315 & 0.469 \\
\hline Involvement $\rightarrow$ Intention & 0.567 & 0.044 & 12.810 & 0.000 & 0.481 & 0.654 \\
\hline Time convenience $\rightarrow$ Involvement & 0.553 & 0.042 & 13.180 & 0.000 & 0.471 & 0.635 \\
\hline Involvement $\rightarrow$ Intention & 0.579 & 0.041 & 14.110 & 0.000 & 0.498 & 0.659 \\
\hline Social interaction $\rightarrow$ Involvement & 0.672 & 0.051 & 13.270 & 0.000 & 0.572 & 0.771 \\
\hline Involvement $\rightarrow$ Intention & 0.589 & 0.042 & 13.960 & 0.000 & 0.506 & 0.672 \\
\hline UI aesthetic $\rightarrow$ Involvement & 0.577 & 0.043 & 13.520 & 0.000 & 0.493 & 0.660 \\
\hline Involvement $\rightarrow$ Intention & 0.582 & 0.042 & 13.850 & 0.000 & 0.499 & 0.664 \\
\hline Portability $\rightarrow$ Involvement & 0.313 & 0.041 & 7.690 & 0.000 & 0.233 & 0.392 \\
\hline Involvement $\rightarrow$ Intention & 0.564 & 0.044 & 12.880 & 0.000 & 0.478 & 0.650 \\
\hline
\end{tabular}

\subsection{Test of Mediation: Attitude}

The verification of mediation effect of attitude is shown in Table 6, Table 7 and Table 8. For the mediation effect of attitude on the relationship between relative advantage (IV) and intention (DV), according to Table 6 , coefficient a1-relative advantage is 0.658 at $p \leq 0.001$, and relative advantage has positive effect on intention when attitude is not included in structure. Table 7 show the path from IV

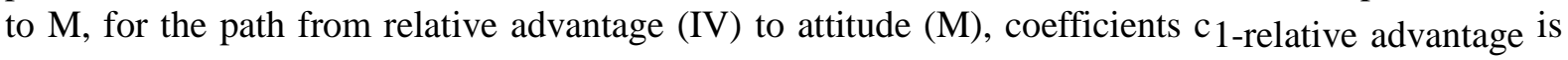
significant (coefficient is 0.597 at $\mathrm{p} \leq 0.001$ ), so, relative advantage (IV) has significant effect on attitude (M). Table 5-9 illustrate model 3, in this test, $c_{2}$-relative advantage (coefficient is 0.660 at 


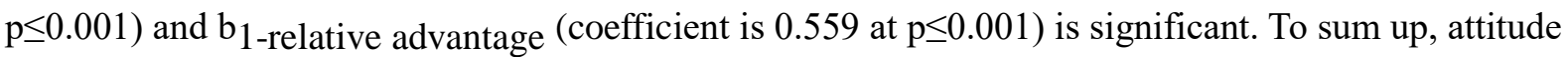
exerts partial mediation effect on the relationship between relative advantage and intention (Table 6). In the same way, the mediation effect of attitude on the relationship between other dependent variable and intention is shown in Table 6.

Table6. Test for $I V \rightarrow D V$ without attention

\begin{tabular}{|l|l|l|l|l|l|l|}
\hline & Coef. & Std. Err. & $\mathrm{z}$ & \multicolumn{2}{l|}{$\mathrm{P}>|\mathrm{z}|$} & \multicolumn{2}{l|}{$[95 \%$ Conf. Interval] } \\
\hline Relative advantage $\rightarrow$ Intention & 0.419 & 0.039 & 10.680 & 0.000 & 0.342 & 0.495 \\
\hline Compatibility $\rightarrow$ Intention & 0.517 & 0.047 & 11.100 & 0.000 & 0.426 & 0.609 \\
\hline Complexity $\rightarrow$ Intention & 0.333 & 0.041 & 8.220 & 0.000 & 0.254 & 0.412 \\
\hline Time convenience $\rightarrow$ Intention & 0.474 & 0.041 & 11.550 & 0.000 & 0.393 & 0.554 \\
\hline Social interaction $\rightarrow$ Intention & 0.588 & 0.052 & 11.330 & 0.000 & 0.486 & 0.689 \\
\hline UI aesthetic $\rightarrow$ Intention & 0.450 & 0.042 & 10.820 & 0.000 & 0.369 & 0.532 \\
\hline Portability $\rightarrow$ Intention & 0.230 & 0.038 & 6.080 & 0.000 & 0.156 & 0.305 \\
\hline Involvement $\rightarrow$ Intention & 0.562 & 0.044 & 12.830 & 0.000 & 0.476 & 0.648 \\
\hline
\end{tabular}

Table7. Test for IV $\rightarrow$ attention

\begin{tabular}{|l|l|l|l|l|l|l|}
\hline & Coef. & Std. Err. & $\mathrm{z}$ & $\mathrm{P}>|\mathrm{z}|$ & \multicolumn{2}{|l|}{$[95 \%$ Conf. Interval] } \\
\hline Relative advantage $\rightarrow$ Attitude & 0.597 & 0.043 & 14.050 & 0.000 & 0.514 & 0.681 \\
\hline Compatibility $\rightarrow$ Attitude & 0.690 & 0.043 & 16.200 & 0.000 & 0.606 & 0.773 \\
\hline Complexity $\rightarrow$ Attitude & 0.410 & 0.046 & 8.870 & 0.000 & 0.319 & 0.500 \\
\hline Time convenience $\rightarrow$ Attitude & 0.556 & 0.042 & 13.250 & 0.000 & 0.473 & 0.638 \\
\hline Social interaction $\rightarrow$ Attitude & 0.596 & 0.060 & 9.870 & 0.000 & 0.478 & 0.714 \\
\hline UI aesthetic $\rightarrow$ Attitude & 0.606 & 0.044 & 13.650 & 0.000 & 0.519 & 0.693 \\
\hline Portability $\rightarrow$ Attitude & 0.337 & 0.042 & 8.070 & 0.000 & 0.255 & 0.419 \\
\hline Involvement $\rightarrow$ Attitude & 0.809 & 0.041 & 19.700 & 0.000 & 0.728 & 0.889 \\
\hline
\end{tabular}

Table8. Test for $I V \rightarrow D V$ with attention

\begin{tabular}{|l|l|l|l|l|l|l|}
\hline & Coef. & Std. Err. & $\mathrm{z}$ & \multicolumn{2}{|l|}{$\mathrm{P}>|\mathrm{z}|$} & \multicolumn{2}{|l|}{ [95\% Conf. Interval] } \\
\hline Relative advantage $\rightarrow$ Attitude & 0.598 & 0.041 & 14.680 & 0.000 & 0.518 & 0.678 \\
\hline Attitude $\rightarrow$ Intention & 0.593 & 0.046 & 12.840 & 0.000 & 0.503 & 0.684 \\
\hline Compatibility $\rightarrow$ Attitude & 0.692 & 0.042 & 16.580 & 0.000 & 0.610 & 0.774 \\
\hline Attitude $\rightarrow$ Intention & 0.595 & 0.045 & 13.130 & 0.000 & 0.506 & 0.684 \\
\hline Complexity $\rightarrow$ Attitude & 0.412 & 0.046 & 9.040 & 0.000 & 0.323 & 0.501 \\
\hline Attitude $\rightarrow$ Intention & 0.589 & 0.045 & 12.970 & 0.000 & 0.500 & 0.679 \\
\hline Time convenience $\rightarrow$ Attitude & 0.560 & 0.041 & 13.820 & 0.000 & 0.480 & 0.639 \\
\hline Attitude $\rightarrow$ Intention & 0.594 & 0.045 & 13.100 & 0.000 & 0.505 & 0.682 \\
\hline Social interaction $\rightarrow$ Attitude & 0.604 & 0.059 & 10.180 & 0.000 & 0.488 & 0.720 \\
\hline Attitude $\rightarrow$ Intention & 0.594 & 0.044 & 13.620 & 0.000 & 0.508 & 0.679 \\
\hline UI aesthetic $\rightarrow$ Attitude & 0.608 & 0.044 & 13.890 & 0.000 & 0.522 & 0.693 \\
\hline Attitude $\rightarrow$ Intention & 0.593 & 0.045 & 13.300 & 0.000 & 0.506 & 0.680 \\
\hline Portability $\rightarrow$ Attitude & 0.243 & 0.037 & 6.580 & 0.000 & 0.171 & 0.316 \\
\hline Attitude $\rightarrow$ Intention & 0.590 & 0.045 & 13.100 & 0.000 & 0.502 & 0.678 \\
\hline Involvement $\rightarrow$ Attitude & 0.810 & 0.041 & 19.940 & 0.000 & 0.730 & 0.889 \\
\hline Attitude $\rightarrow$ Intention & 0.596 & 0.045 & 13.260 & 0.000 & 0.508 & 0.684 \\
\hline
\end{tabular}

\section{RESEARCH CONCLUSION}

Based on the integration of technology acceptance model, innovation diffusion theory and software quality model, this study proposes a research model, in line with the existing research results, and put forward corresponding hypotheses. Through detailed questionnaires, collection of questionnaires and data preprocession, the consequence shows that the measurement model, with a high degree of fitness, and the reliability, aggregation validity and differential validity have a good performance. And most of the hypotheses are verified. The results of the study confirm that application design attributes and application performance attributes are important factors driving the adoption of mobile travel applications. 
This research mainly has three contributions. Firstly, the thesis puts forward the initiative a model of the influence mechanism of the mobile-end tourism service app use intention for the first time. Secondly, this study theoretically analyzes and explains the mediation influence mechanism of this effect. Thirdly, this study innovates the combination of the novel perception characteristics organic with the mobile phone app use intention.

In this study, research still exists some limitations. First of all, the quantity of the sample is a bit of small. Secondly, this study mainly chooses the traditional Chinese cultural scenic spots in the urban commercial district. Besides, the research model may have missed some important variables. Consumer behavior is ever-changing, affecting consumer behavior due to different scenarios, different factors, cultural factors, personal factors, psychological factors, social factors, political factors, etc.

\section{BIBLIOGRAPHY}

[1] 李东和张鹭旭. (2015). 基于Tam的旅游App下载使用行为影响因素研究[J]. 旅游学刊(08), 29-37.

[2] Lu, J., Mao, Z., \& Wang, M. (2015) Goodbye maps, hello apps? Exploring the influential determinants of travel app adoption. Current Issues in Tourism, 18(11), 1-21.

[3] Amaro, S. \& Duarte, P. (2015). An integrative model of consumers' intentions to purchase travel online. Tourism Management, 46, 64-79.

[4] Agag, G. \& El-Masry, A. A. (2016). Understanding the determinants of hotel booking intentions and moderating role of habit. International Journal of Hospitality Management, 54, 52-67.

[5] Jensen, J. M. (2009). Travellers' intentions to purchase travel products online: The role of shopping orientation. Advances in Tourism Economics, 203-215.

[6] Kang, J. M., Mun, J. M., \& Johnson, K. K. (2015). In-store mobile usage: Downloading and usage intention toward mobile location-based retail apps. Computers in Human Behavior, 46, 210-217.

[7] Rogers, E. M. (1995). Diffusion of Innovations: modifications of a model for telecommunications. Die Diffusion von Innovationen in der Telekommunikation, 25-38.

[8] Sonnenwald, D. H., Maglaughlin, K. L., \& Whitton, M. C. (2001). Using innovation diffusion theory to guide collaboration technology evaluation: Work in progress. Enabling Technologies: Infrastructure for Collaborative Enterprises, 2001. WET ICE 2001. Proceedings. Tenth IEEE International Workshops on, 114-119.

[9] Zaichkowsky, J. L. (1994). The personal involvement inventory: Reduction, revision, and application to advertising. Journal of advertising, 23(4), 59-70.

[10] Jiang, Z., Chan, J., Tan, B. C., \& Chua, W. S. (2010). Effects of interaction on website involvement and purchase intention. Journal of the Association for Information Systems, 11(1), 34-59.

[11] Huang, C. Y., Chou, C. J., \& Lin, P. C. (2010). Involvement theory in constructing bloggers' intention to purchase travel products. Tourism Management, 31(4), 513-526.

[12] Miguel, J. P., Mauricio, D., \& Rodríguez, G. (2014). A review of software quality models for the evaluation of software products. arXiv preprint arXiv:1412.2977.

[13] Rogers, E. M.(2003).Diffusion of innovations (5th ed.).New York, NY:Free Press.

[14] Zolkepli, I. A. \& Kamarulzaman, Y. (2015). Social media adoption: The role of media needs and innovation characteristics. Computers in Human Behavior, 43, 189-209.

[15] Helge Thorbjørnsen, Per E. Pedersen, \& Herbjørn Nysveen. (2007). "this is who i am": identity expressiveness and the theory of planned behavior. Psychology \& Marketing, 24.

[16] Premkumar, G. (2015). Implementation of Electronic Data Interchange: An Innovation Diffusion Perspective. Journal of Management Information Systems, 11(2), 157-186.

[17] Tojib, D. \& Tsarenko, Y. (2012). Post-adoption modeling of advanced mobile service use. Journal of Business Research, 65(7), 922-928.

[18] González, M. I. M. \& Cavia, J. F. (2015). Tourism and online communication: interaction and social web in official destination websites. Communication \& Society, 28,17-31.

[19] Mpinganjira, M. (2016). Influencing consumer engagement in online customer communities: The role of interaction. Acta Commercii, 16(1), 1-10.

[20] Hu, M., Zhang, M., \& Luo, N. (2016). Understanding participation on video sharing communities: The role of self-construal and community interaction. Computer in Human Behavior, 62(C), 105-115.

[21] Twan, Peters, Öykü, Işık, Olgerta, \& Tona, et al. (2016). How system quality influences mobile bi use: the mediating role of engagement. International Journal of Information Management.

[22] Bhatti, T. (2015). Exploring factors influencing the adoption of mobile commerce. The Journal of Internet Banking and Commerce. 
[23] Bruner, G. C. \& Kumar, A. (2005). Explaining consumer acceptance of handheld Internet devices. Journal of Business Research, 58(5), 553-558.

\section{AUTHOR'S BIOGRAPHIES}

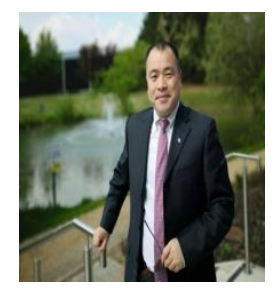

Ruping Wang, Doctor of Management. Inventor of C Management model and Business Compass theory. A co-authored paper has entered the Highly Cited Paper series, and has entered the top 1\% of ESI. The paper "Characteristics and Mission of Management Thinking with Chinese Characteristics Based on the Business Compass Perspective" was rated as an excellent paper by the 8th International Symposium on Project Management.

Citation: Wang Ruping, et.al. "A Study on the Adoption Intention of Tourism Users' Applications" International Journal of Humanities Social Sciences and Education (IJHSSE), vol 7, no. 7, 2020, pp. 161-170. doi: http://dx.doi.org/10.20431/2349-0381.0707019.

Copyright: (C) 2020 Authors. This is an open-access article distributed under the terms of the Creative Commons Attribution License, which permits unrestricted use, distribution, and reproduction in any medium, provided the original author and source are credited. 